\title{
O gênero Catopsis (Bromeliaceae: Tillandsioideae) no estado do Paraná: aspectos taxonômicos e anatômicos
}

The genus Catopsis (Bromeliaceae: Tillandsioideae) in the Paraná state: taxonomic and anatomical aspects

\author{
Jaqueline Priscila Bispo de Almeida Cardoso Marcondes ${ }^{1,2}$, Rosângela Capuano Tardivo ${ }^{1}$, \\ Vanessa Koza Kowalski ${ }^{1} \&$ Maria Eugênia Costa $^{1}$
}

\begin{abstract}
Resumo
Catopsis está representado por 19 espécies distribuídas entre as três Américas. No Brasil, são citadas duas espécies, Catopsis berteroniana encontada nas regiões Nordeste, Sudeste e Região Sul e Catopsis sessiliflora, com uma abrangência mais ampla, encontrada também na Região Norte. Morfologicamente, o gênero diferenciase na subfamília Tillandsioideae pela presença de apêndices apenas no ápice das sementes. Neste trabalho foram realizados o estudo taxonômico e morfoanatômico das espécies de Catopsis no estado do Paraná. Para isso, foram realizadas expedições botânicas de Jul/2013-Jun/2014 e visitas aos herbários HUPG, MBM e UPCB. Os exemplares coletados foram identificados e herborizados, e as exsicatas depositadas no HUPG. Para o estudo morfoanatômico foram confeccionadas lâminas semipermanentes da região mediana da bainha e da folha a partir de secções transversais e longitudinais obtidas a mão livre e montadas em gelatina glicerinada, ainda, foram desidratadas porções da folha e da bainha para observação em Microscopia Eletrônica de Varredura. Como resultados, são apresentadas descrições morfológicas, período de floração e frutificação, chaves de identificação, mapa de distribuição geográfica, classificação ecofisiológica, comentários sobre a morfologia e anatomia das espécies, ilustrações e o status de conservação dos táxons estudados.
\end{abstract}

Palavras-chave: anatomia foliar, flora do Paraná, taxonomia.

\begin{abstract}
Catopsis is represented by 19 species distributed among the three Americas. Two species occurs in Brazil, Catopsis berteroniana distributed in Northeast, Southeast and South region and Catopsis sessiliflora, with a broadly distribution, also found in the North. The aim of this work was to perform a taxonomic and morphoanatomic study of the species of Catopsis occuring in Paraná state. In order to do so, botanical expeditions occurred during the periods of Jul/2013-Jun/2014 just as the visits to HUPG, MBM and UPCB herbarium. The collected specimens were identified, herborized, and deposited in the HUPG herbarium. For the morphoanatomic study semi-permanent slides were prepared from the middle region of the sheath and leaf from transverse and longitudinal sections obtained free hand and mounted in glycerinated gelatin. For Scanning Electron Microscopy analysis portions of leaf blade and sheath were dehydrated for observation. As results, we provide descriptions, period of flowering and fruiting, identification keys, geographic distribution, the ecophysiological rating, morphology and anatomy comments, and conservation status of the species.
\end{abstract}

Key words: leaf anatomy, flora of Paraná, taxonomic study.

\section{Introdução}

Bromeliaceae é representada por 3.910 espécies distribuídas em 67 gêneros (Butcher \& Gouda, cont. updated). A família está atualmente subdividida em oito subfamílias monofiléticas,
Bromelioideae, Tillandsioidae, Hechtioideae, Puyoideae, Pitcairnioideae, Lindmanioideae, Brocchinioideae e Navioideae (Givnish et al. 2007; Givnish et al. 2011). Distribui-se praticamente em todos os ecossistemas compreendidos entre o sul

\footnotetext{
${ }^{1}$ Universidade Estadual de Ponta Grossa, Campus Uvaranas, Av. General Carlos Cavalcanti 4748, 84030-900, Ponta Grossa, PR, Brasil

${ }^{2}$ Autor para correspondência: jaquelinepriscila.marcondes@gmail.com
} 
dos Estados Unidos e a região central da Argentina e Chile. Tem como centros de diversidade quatro regiões montanhosas, incluindo América Central, o Andes, o Escudo das Guianas, e a Serra do Mar e faixas costeiras próximas do Escudo Brasileiro na América do Sul. Sendo estes três últimos, os centros de desenvolvimento e dispersão mais importantes, e a América central provável local de origem. No Brasil a família possui 1349 espécies, das quais 1177 são endêmicas (BFG 2015). A maior representatividade no país, tanto no aspecto de diversidade (924 espécies) como no de quantidade ocorre na Mata Atlântica (Leme \& Maringo 1993; Martinelli et al. 2008; Givnish et al. 2011; BFG 2015). Bromeliaceae é um dos grupos taxonômicos mais relevantes na Mata Atlântica, principalmente por seu elevado grau de endemismo, diversidade de espécies e por sua capacidade de abrigar comunidades devido ao acumulo de água na roseta foliar, desde bactérias a vertebrados (anuros) (Benzing 2000; Schuttz et al. 2012).

O gênero Catopsis Griseb. enquadra-se na subfamília Tillandsioideae e diferencia-se dos demais gêneros pela presença de apêndices apenas no ápice das sementes, sendo esta, uma apomorfia do grupo (Barfuss et al. 2005; Givnish et al. 2007). Nas Américas, 19 espécies são registradas (Reitz 1983; Wanderley et al. 2007; Luther 2014), sendo duas delas presentes no Brasil, Catopsis berteroniana (Schult. \& Schult f.) Mez e Catopsis sessiliflora (Ruiz \& Pav.) Mez (BFG 2015). Estas espécies são encontradas no Bioma Mata Atlântica, sendo que $C$. berteroniana ocorre em mata de restinga e manguezais e $C$. sessiliflora em mata de restinga (Martinelli et al. 2008). Segundo Wanderley et al. (2007) ambas estão presentes nos corredores de Biodiversidade da Mata Atlântica: Corredor Central, Serra do Mar e Nordeste.

Anatomicamente, a família possui características foliares próprias, como células epidérmicas com paredes sinuosas, presença de corpos de sílica e presença de tricomas foliares peltados (Tomlinson 1969). Os tricomas são formados por um pedicelo e um escudo posicionado paralelamente à superfície foliar, responsável pela captação e transporte de água e nutrientes. Além de sua importância evolutiva, os tricomas variam em número e posição das células que o compõe, sendo uma característica usual para delimitação das subfamílias, gêneros e espécies (Strehl 1983).

Este trabalho descreve espécies do gênero Catopsis encontrados no Estado do Paraná, com enfoque taxonômico, informações de floração, frutificação, distribuição geográfica e status de conservação, além de destacar as características da anatomia foliar, auxiliando na identificação dos táxons e compreensão das relações adaptativas ao ambiente.

\section{Material e Métodos}

Para os estudos morfológicos e taxonômicos, além do material coletado, foram analisadas as coleções dos herbários nacionais (MBM, HUPG e UPCB), cujos acrônimos estão de acordo com Thiers (2017). Os exemplares férteis coletados foram herborizados segundo as técnicas usuais da taxonomia vegetal (Fidalgo \& Bononi 1989; Peixoto \& Maia 2013) e as exsicatas foram depositadas no Herbário da Universidade Estadual de Ponta Grossa (HUPG).

A identificação do material coletado foi realizada com base em Smith \& Downs (1977), Reitz (1983) e análise das descrições originais e imagens dos typus. A terminologia morfológica foi baseada em Radford et al. (1974), Stearn (1983), Scharf \& Gouda (2008) e Gonçalves \& Lorenzi (2011). As descrições dos táxons foram baseadas em material in vivo e em literatura (Reitz 1983; Smith \& Downs 1977; Wanderley et al. 2007).

A distribuição geográfica das espécies foi baseada nas coletas realizadas e no levantamento das coleções dos herbários e o status de conservação dos táxons foi baseado nos critérios e categorias estabelecidos pela IUCN (2016).

Para a análise anatômica foram retiradas três folhas medianas da roseta de três exemplares diferentes de cada espécie. O material foi fixado em FAA 50 e preservado em etanol 70\%. Secções transversais, longitudinais e paradérmicas da região central da lâmina foliar e da bainha, foram obtidas à mão livre com o auxílio de lâmina de barbear, coradas com Azul de Astra e Fucsina Básica e montadas em lâminas histológicas, com gelatina glicerinada (Kraus \& Arduin 1997).

Para identificação de amido, lipídeos e lignina foram utilizados Lugol (Johansen 1940), Sudan III (Sass 1951) e Floroglucina Acidificada (Berlyn \& Miksche 1976), respectivamente.

A descrição do material foi feita através das observações em microscópio óptico. As fotomicrografias foram obtidas com máquina digital SONY DSC-W210 acoplada ao microscópio Olympus CX21FS1, acrescentando-se escalas nas condições ópticas adequadas.

Para melhor definição dos tipos de tricomas, estômatos e cera, foram desidratadas porções da 
região mediana da folha e da bainha em série etanólica (Haddad et al. 1998), em seguida, as amostras foram aderidas sobre suportes de alumínio, metalizadas, observadas e fotografadas em Microscópio Eletrônico de Varredura (MEV), Vega3/Tescan.

\section{Resultados e Discussão}

Catopsis Grisebach, Fl. Brit. W. Indies 599. Oct. 1864.

Erva epífita 15-92 cm alt. quando fértil. Rizoma curto. Roseta utriculosa. Folhas 7-13, liguladas, amplexicaules, lepidota em ambas as faces; bainha esverdeada, invaginante, coriácea, pouco distinta da lâmina, linear, gradativamente mais estreita que a lâmina foliar; lâmina verde, membranácea, elíptica, margem inteira, cerosa em ambas as faces. Inflorescência espigada para qualquer lado, laxiflora, simples ou composta, glabra, inerme; escapo glabro, inicialmente ereto e levemente recurvado frutificado; brácteas do escapo verdes, eretas, foliáceas, margem inteira e membranácea; brácteas florais verdes, ovaladatriangular, mais curta que as sépalas, com porção basal envolvendo o escapo. Flores 6-12 mm; sépalas 3 , verdes ou verdes amareladas, foliáceas, elípticas ou obovada, ápice obtuso com a margem involuta, margem inteira e membranácea; pétalas alvas, oval-lanceoladas, membranácea; estames anisostêmone em duas séries de três, menores que as pétalas e gineceu; filetes achatados; anteras rimosas, sagitadas, basifixa. Ovário supero, triangular, trilocular, gamocarpelar, glabro. Estiletes 3. Estigma 3, puntiformes. Cápsula septicída, apiculada, com três faces distintas achatadas da porção mediana ao ápice, trilocular, ovóide, coloração verde quando imatura e castanho a branco quando maduras. Sementes numerosas, aladas, com apêndices (tricomas) filiformes no ápice, várias vezes dobrados.

\section{Chave de identificação das espécies de Catopsis do estado do Paraná}

1. Erva 70-92 cm alt. quando fértil; brácteas do escapo cimbiformes, as basais mais longas que os entrenós e as apicais menores; sementes 3,5-4,0 cm compr., tegumento branco-dourado e apêndices esbranquiçados; cera epicuticular formada por bastões longos que se recurvam formando grandes aglomerados; estômatos presentes em ambas às faces da lâmina foliar; hipoderme abaxial da bainha com paredes lignificadas, delgadas a extremamente espessas 1. Catopsis berteroniana

1'. Erva 15-33 cm alt. quando fértil; brácteas do escapo triangulares, mais curtas que os entrenós; sementes 2,5-2,8 cm compr., tegumento marrom-dourado e apêndices ocre-dourado, cera epicuticular formada por bastões curtos não aglomerados; estômatos presentes apenas na face abaxial da lâmina foliar; hipoderme da bainha com paredes não lignificadas e sempre delgadas

2. Catopsis sessiliflora

1. Catopsis berteroniana (Schult. \& Schult. f.) Mez, Monogr. Phan. 9: 621. $1896 . \quad$ Fig. 1a-e Erva epífita 70-92 cm alt. quando fértil. Folhas 7-13, com a porção basal e média eretas, formando uma roseta convergente-utriculosa, densamente lepidota em ambas as faces, 25-35 $\times 4,5-6 \mathrm{~cm}$; bainha densamente coberta por cera epicuticular na face adaxial, o que lhe confere aspecto aveludado branco; lâmina com ápice cuspidado deflexo, coberta densamente por cera nas porções média e inferior de ambas as faces, de aspecto aveludado branco. Inflorescência composta. Escapo 3-7 ramos, 69,5-91,5 cm compr., 25-50 mm diâm.; brácteas do escapo 9-13, cimbiformes, ápice cuspidado deflexo, imbricadas na porção basal, com tamanho crescente do ápice a base 10-200 × 10-37 mm, brácteas basais muito mais longa que os entrenós e brácteas apicais menores que o entrenós. Brácteas florais 5-7 × 5-6 mm. Flores 6-12 mm; sépalas verde-amarelado, obovada, $8-10 \times 6-8$ $\mathrm{mm}$; pétalas 8-9 $\times 3,5-4 \mathrm{~mm}$; estames menores ca. $5,5 \mathrm{~mm}$ e maiores ca. 7,5 $\mathrm{mm}$; anteras ca. 1,5 $\mathrm{mm}$ compr. Ovário 6-12 mm ca. $7 \mathrm{~mm}$. Estiletes ca. 1,5 mm compr. Cápsula 10-15 × 7-8 mm. Sementes 35-40 mm compr. incluindo seus apêndices, apêndices 30-35 mm compr., dobrados 4-5 vezes, tegumento branco-dourado e apêndices esbranquiçados.

Catopsis berteroniana foi encontrada em Pontal do Paraná, Guaratuba e na Ilha do Mel, Unidade de Conservação, dentro do complexo estuário da Baía de Paranaguá, em mata de restinga e manguezais (Fig. 2). Coletada com flores em fevereiro e março e frutos em abril, maio e julho. 

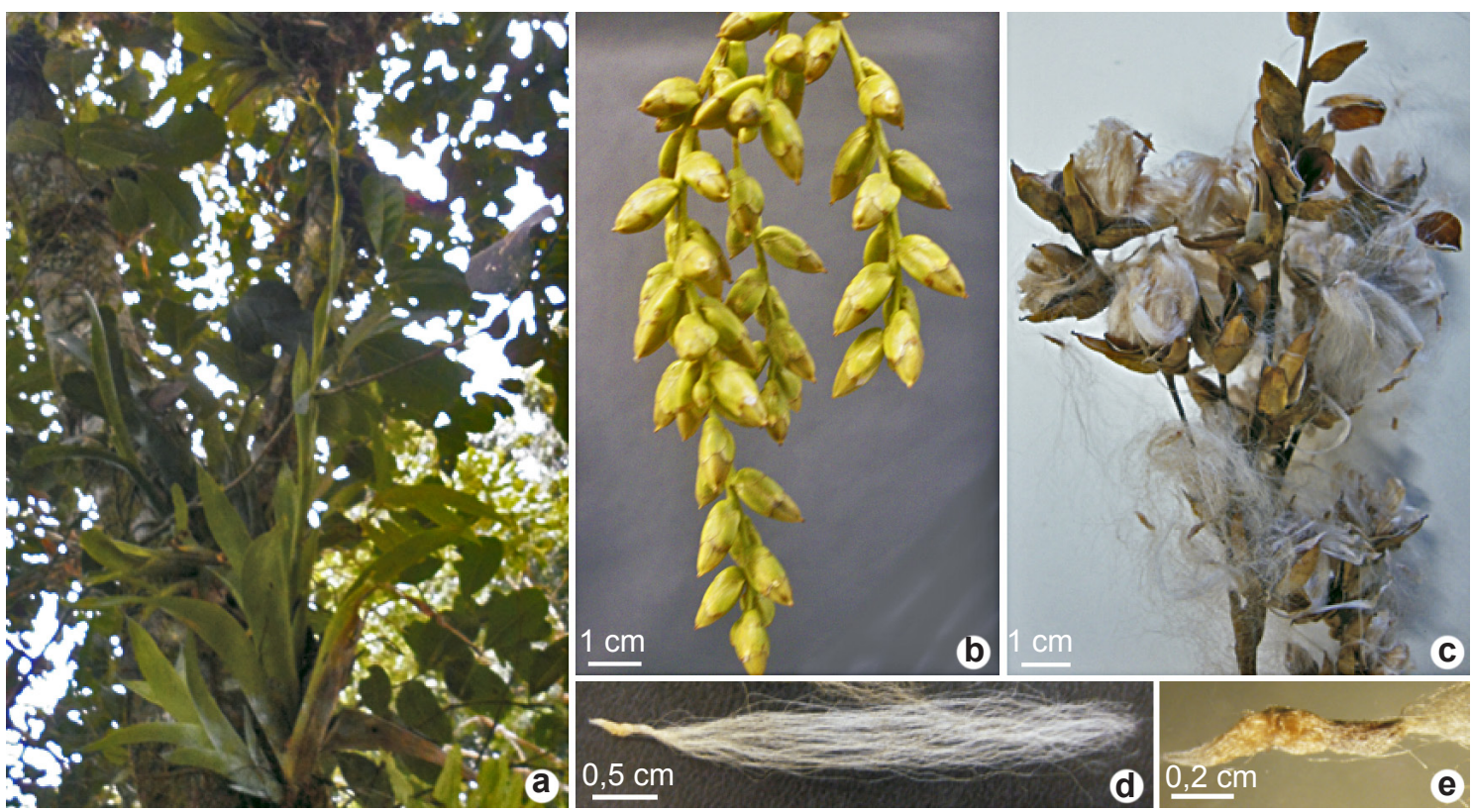

Figura 1 - a-e. Catopsis berteroniana - a. hábito; b. fruto imaturo; c. fruto maduro; d. semente; e. detalhe do tegumento da semente.

Figure 1 - a-e. Catopsis berteroniana - a. habit; b. immature fruit; c. ripe fruit; d. seed; e. seed integument detail.

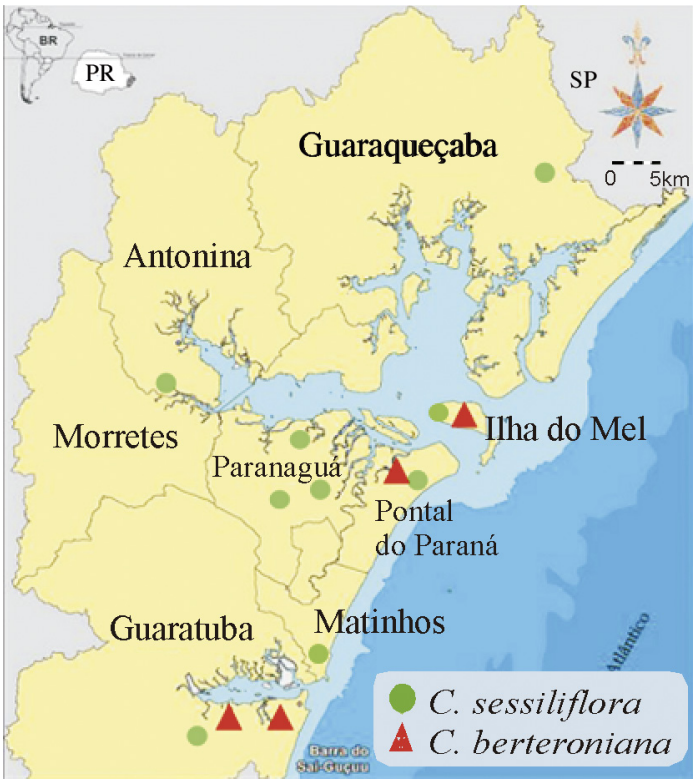

Figura 2 - Distribuição geográfica do gênero Catopsis Griseb no estado do Paraná. Fonte: Mapa Adaptado de REBIMAR. Figure 2 - Geographical distribution of the genus Catopsis Griseb in Paraná State. Source: Map adapted from REBIMAR.

Material examinado: Guaratuba, Rio da Capivara, 30.III.1997, fl., J.M. Silva \& E.V. Odia 1915 (MBM); Rio Quiririm, 1.IV.1973, fl., G. Hatschbach 31800
(MBM). Paranaguá, Ilha do Mel, Reserva Ecológica, 13.III.1987, bfl., R.M. Britez 1399 (UPCB); 28.V.1988, fl., W.S. Souza 1299 (MBM); Pontal do Paraná, Guapé, 28.VII.2014, fr., J.P.B.A.C. Marcondes 09 (HUPG); 28.VII.2014, fr., J.P.B.A.C. Marcondes 23 (HUPG).

2. Catopsis sessiliflora (Ruiz \& Pav.) Mez, Monogr. Phan. 9: 625. 1896.

Fig. 3a-e

Erva epífita $15-33 \mathrm{~cm}$ alt. quando fértil. Folhas 9-10, 10-25 × 2-4 cm; lâmina das folhas medianas com ápice acuminado-mucronado e as externas e internas com ápice cuspidado, ambas as faces com fina camada de cera, principalmente sobre a região mediana na face adaxial e inferior na face abaxial. Inflorescência geralmente não ramificada. Escapo 1-2 ramos, 15-32 cm compr., 1-2 mm diâm.; brácteas do escapo 8-9, triangulares, ápice apiculado 6-11 × 5-6 mm, mais curta que o entrenós. Bráctea floral $8-10 \times 4-5$ $\mathrm{mm}$. Flores ca. $9 \mathrm{~mm}$; sépalas verdes, elípticas, 6-8 × 5-6 mm; pétalas ca. $6,5 \times 2 \mathrm{~mm}$; estames menores ca. $4 \mathrm{~mm}$ e maiores ca. $5 \mathrm{~mm}$; anteras ca. $1 \mathrm{~mm}$ compr. Ovário ca. $9 \times 4 \mathrm{~mm}$ por a largura. Estiletes ca. 1,4 mm compr. Cápsula 9-13 × 4-5 $\mathrm{mm}$. Sementes $25-28 \mathrm{~mm}$ compr. incluindo seus apêndices, apêndices 21-24 mm compr., dobrado 3-4 vezes, tegumento marrom-dourado e apêndices ocre-dourados. 



Figura 3 - a-e. Catopsis sessiliflora - a. hábito; b. fruto imaturo; c. fruto maduro; d. semente; e. detalhe do tegumento da semente.

Figure 3 - a-e. Catopsis sessiliflora - a. habit; b. immature fruit; c. ripe fruit; d. seed; e. seed integument detail.

Catopsis sessiliflora foi encontrada na mata de restinga, no litoral, nos municípios de Antonina, Paranaguá, Pontal do Paraná, Guaraqueçaba, Guaratuba e Matinhos, e no manguezal de Guaratuba, habitando altura inferior a três metros do solo e em locais de até $500 \mathrm{~m}$ de altitude (Fig. 2). Coletada com flores em março, abril e julho e frutos em março, maio, junho, julho e dezembro.

Material examinado: Antonina, Reserva Biológica de Sapitanduva, 5.III.1995, fr., G. Hatschbach 61744 (MBM). Guaraqueçaba, Rio do Cedro, 27.II.1969, fl., G. Hatschbach 21193 (MBM). Matinhos, Parque Estadual Rio da Onça, 29.XII.2004, fr., R. Morokawa 20 (UPCB). Paranaguá, Baia-Paranaguá/Piaçaguera, 23.IV.1969, fr., G. Hatschbach 21407 (MBM); Colônia Santa Cruz, 30.IV.1975, fr., G. Hatschbach 34874 (MBM); Rio Guaraguaçu, 28.VII.1973, fr., G. Hatschbach 32248 (MBM); 24.V.2012, fr. G. Felitto 289 (MBM); 14.VI.2013, fr. J.P.B.A.C. Marcondes, et al. 04 (HUPG); Ilha do Mel, Reserva Ecológica, 18.IV.1999, fr. M.P. Petean 45 (UPCB). Pontal do Paraná, bairro Guapé, 2.XII.2013, fr. J.P.B.A.C. Marcondes 03 (HUPG); 2.XII.2013, fr. J.P.B.A.C. Marcondes 05 (HUPG); 2.XII.2013, fr. J.P.B.A.C. Marcondes 06 (HUPG); 2.XII.2013, fr. J.P.B.A.C. Marcondes 07 (HUPG); 2.XII.2013, fr. J.P.B.A.C. Marcondes 08 (HUPG).

\section{Status de conservação}

Conforme os critérios da IUCN, ambos os táxons se enquadram na categoria Vulnerável(VU), pela intensa degradação da Floresta no estado, colocando em risco as espécies do Bioma Mata Atlântica.

Ao longo da pesquisa constatou-se deterioração dos Mangues e da Floresta Ombrófila
Mista do Paraná, destacando-se a redução da flora pelo avanço das construções irregulares e a poluição pelo lançamento de esgoto e deposições de lixos. Problemas já observados por Estades (2003), Depiné \& Fiori (2005) e Pierriet al. (2006).

\section{Anatomia foliar das espécies} de Catopsis encontradas no Paraná

Cera: ambas as espécies apresentam cera epicuticular ao longo das duas faces da folha, sendo a região médio-abaxial, em geral, local de maior concentração. A alta densidade de cera confere aspecto aveludado-esbranquiçado à folha (Fig. 4 a,b). A superfície das folhas de $C$. berteroniana é coberta por grande quantidade de cera constituída por bastões longos que se recurvam formando grandes emaranhados nas regiões de maior concentração (Fig. 4c), já em $C$. sessiliflora a cera está em menor quantidade, se dispõe em bastões curtos não aglomerados (Fig. 4d). C. berteroniana, que possui densidade elevada de cera, foi encontrada em ambientes abertos exposta a alta incidência de luz, diferente de $C$. sessiliflora que possui uma fina camada de cera, e foi encontrada no estrato médio-baixo da floresta, sem incidência direta de luz. Palacíet al. (2004) e Benzing (2000) relacionam essa localização com a densidade de cera, onde as espécies com maior densidade de cera ocupam os níveis mais elevados na copa das árvores, e habitats totalmente expostos no perfil da floresta. Isso provavelmente ocorre, pois, a presença da cera proporciona as espécies 

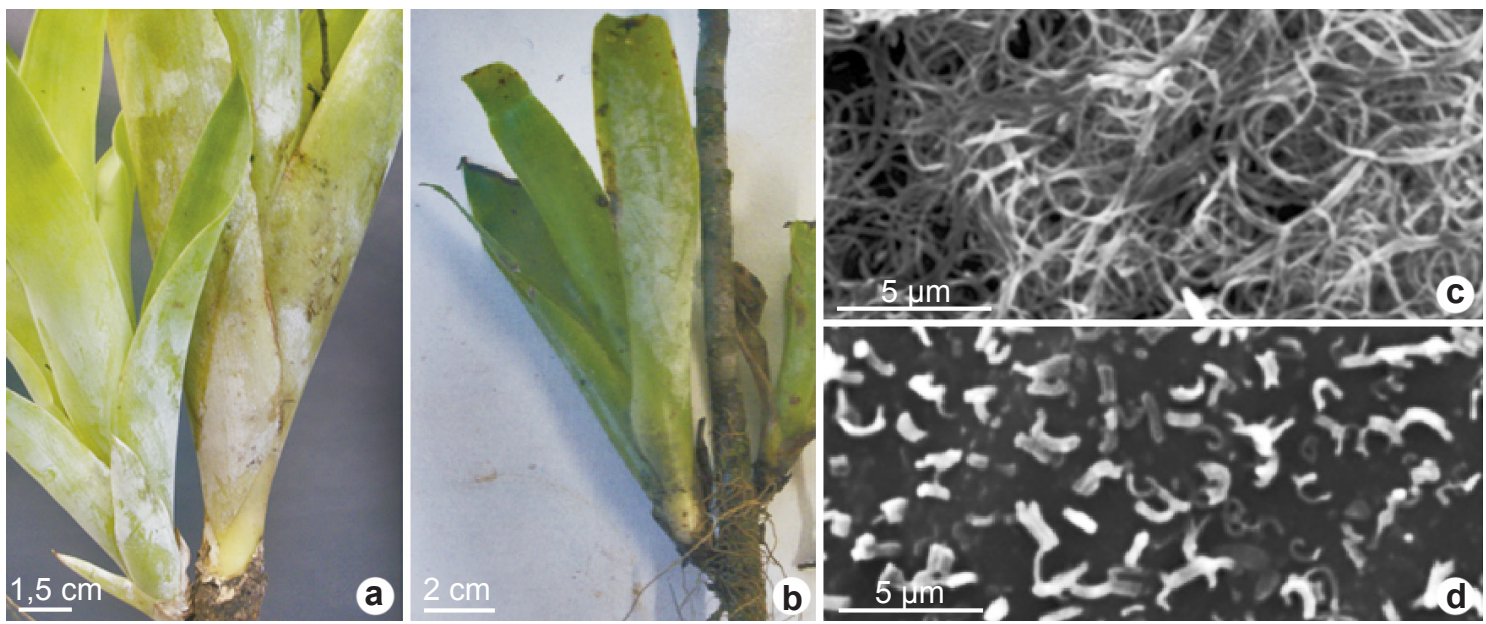

Figura 4 - a. detalhe da cera na face abaxial de Catopsis berteroniana; b. detalhe da cera na face abaxial da folha de C. sessiliflora; c. detalhe da morfologia da cera epicuticular de C. berteroniana (face abaxial da folha); d. detalhe morfológico da cera epicuticular de C. sessiliflora (face adaxial da folha).

Figure 4 - a. detail of wax on the abaxial surface of Catopsis berteroniana; b. detail of wax on the abaxial surface of C. sessiliflora; c. detail morphology the wax of $C$. berteroniana (abaxial leaf surface); d. detail morphology the wax of C. sessiliflora (adaxial leaf surface).

proteção contra o stress hídrico, por fornecer uma barreira hidrofóbica na superfície da planta (diminui a perda de água) e proteção contra a incidência de raios UV na folha, uma vez que os reflete (Kolattukudy 1980). Em C. berteroniana a cera ainda é uma das principais estruturas responsáveis por seu modo de vida protocarnívora, pois, permite sua exposição a locais abertos onde são facilmente encontradas por insetos voadores, e possibilita sua captura (Fish 1976). A presença de cera é uma característica frequente no gênero Catopsis, sendo classificada como o tipo "Strelitzia" devido a sua forma de deposição em forma de hastes com projeções de aparência maciça, o que dá a folha uma aparência cretácea (Palací et al. 2004).

Tricomas: os tricomas peltados absorventes são formados pelo escudo e pedúnculo (Figs. 5a-e). O escudo é simétrico, composto por quatro células centrais, circundadas por oito células pericentrais e radialmente pelas células da ala (Figs. 5a,b). As células da ala são levemente alongadas, com ápice agudo arredondado, em $C$. sessiliflora estas variam de 20-36 (Figs. 5a,b), e em C. berteronianade 33-50 (Fig. 5c). A maior diferença entre a quantidade de células da ala e de seu alongamento ocorre na bainha (Fig. 5c). Em geral, as células pericentrais do escudo apresentam paredes retas, contudo, em tricomas com grande número de células da ala, como ocorre na bainha foliar de $C$. berteroniana, as paredes subjacentes à ala são sinuosas (Fig. 5c). Algumas células da ala e pericentrais dos tricomas apresentaram conteúdos citoplasmáticos evidenciados, tanto na lâmina foliar como na bainha (Fig. 5c). O que pode indicar que estas células são vivas, assim como o encontrado por Kowalski et al. (2016) em Vriesea. No entanto não foram realizados testes de permeabilidade e integridade de membrana para se comprovar tal hipótese.

O pedúnculo é unisseriado, localizado em depressões agudas da epiderme, sendo constituído por cinco ou seis células (Figs. $5 \mathrm{~d}$,e): duas células basais, duas a três intermediárias estreitas, alongadas periclinalmente e uma apical volumosa com parede periclinal externa convexa (Figs. 5d,e). O comprimento dessas células acompanha a abertura da depressão epidérmica, aumentando gradativamente da base ao ápice (Figs. 5d,e). As células do pedúnculo, em geral, possuem um conteúdo citoplasmático denso, apresentando coloração castanho escuro à preto em $C$. berteroniana (Fig. $5 \mathrm{~d}$ ) e castanho claro em $C$. sessiliflora. Já nas centrais do escudo, pericentrais e da ala, apesar de evidentes, não apresentam esta coloração. (Figs. 5d,e). Essa diferença de cor no conteúdo citoplasmático pode estar relacionada, ao fato de $C$. berteroniana ser uma espécie protocarnívora, e ter maior disponibilidade de matéria orgânica em sua roseta, e consequentemente maior absorção de nutrientes.

Os tricomas peltados absorventes estão distribuídos em ambas às faces da lâmina foliar e bainha, possuem distribuição aleatória (Fig. 5f) e 

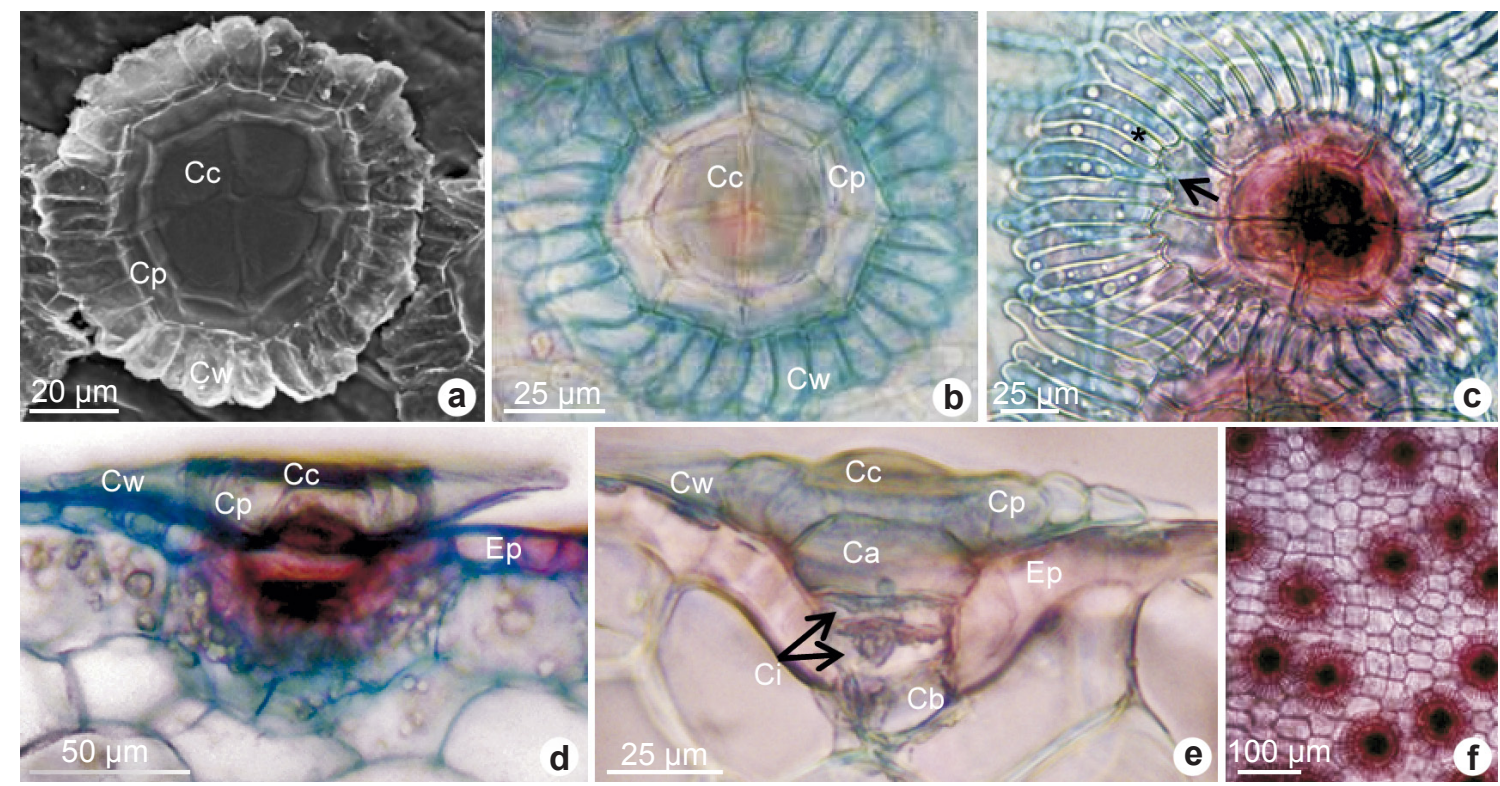

Figura 5 - a-f. Tricomas de Catopsis - a. microscopia eletrônica da face abaxial da lâmina de Catopsis sessiliflora, detalhe do escudo; b. secção paradérmica da face abaxial da bainha de $C$. sessiliflora, detalhe do escudo; c. secção paradérmica da face adaxial da bainha de $C$. berteroniana, detalhe do escudo, sinuosidade da parede das células pericentrais do escudo (seta), conteúdos citoplasmáticos evidenciado nas células da ala (*); d. secção transversal da bainha de $C$. berteroniana, detalhe do pedunculo; e. secção transversal da bainha de $C$. sessiliflora, detalhe do pedunculo; f. secção paradérmica da face abaxial da bainha de $C$. berteroniana $. \mathrm{Ca}=$ célula apical; $\mathrm{Cb}=\mathrm{células}$ basais; $\mathrm{Cc}=$ células centrais; $\mathrm{Ci}=$ células intermediárias; $\mathrm{Cp}=$ células pericentrais; $\mathrm{Cw}=$ células da ala (periféricas); $\mathrm{Ep}=$ célula epidérmica.

Figure 5 - a-f. Trichomes of Catopsis - a. electron microscopy of the lower face of the leaf of Catopsis sessiliflora, detail of the shield; b. paradermic section of the lower face of sheath of C. sessiliflora, detail of the shield; c. paradermic section of the lower face of sheath of $C$. berteroniana, detail of the shield, sinuous wall of the shell pericentral cells (arrow), cytoplasmic contents evidenced in wings cells $(*)$; d. cross section of leaf sheath of $C$. berteroniana, detail of the peduncle; e. cross section of leaf sheath of $C$. sessiliflora, detail of the peduncle; $\mathrm{f}$. paradermic section of the lower face of sheath of $C$. berteroniana, distribution of trichomes. $\mathrm{Ca}=$ apical cell; $\mathrm{Cb}=\mathrm{basal}$ cell; $\mathrm{Cc}=$ central cells; $\mathrm{Ci}=$ intermediary cells; $\mathrm{Cp}=$ pericentral cells; $\mathrm{Cw}=$ wing cells; $\mathrm{Ep}=$ epidermal cell.

densidade maior na bainha foliar. Sua distribuição aleatória corrobora o encontrado por Derwidueé \& Gonzalez (2010), que relatam esta distribuição para espécies de bromélias com epiderme lisa, onde estão ausentes os sulcos. Kowalski (2013) e Freschi et al. (2010) afirmam que a maior concentração na bainha evidencia a relação dos tricomas com o modo de vida das espécies, que em época de estiagem usam seus tanques para obtenção de água e matéria orgânica. Além da função de absorver água e sais minerais, os tricomas reduzem a transpiração e a insolação da folha, por formarem uma proteção mecânica (Tomlinson 1969; Benzing 2000). Em uma mesma folha, variações numéricas e morfológicas são observadas nos tricomas (Strehl 1983). Numericamente, como visto por Tomlinson (1969) as células do pedúnculo variam de 3-4 (excluindo as duas células basais); quanto ao número de células da ala Tomlinson (1969) relatou em $C$. berteroniana uma discreta variação no número dessas células, no entanto neste estudo foi encontrado em ambas as espécies, uma variação significativa. Morfologicamente, as células da ala variam em uma mesma folha quanto a largura, comprimento e formato do ápice, o que também foi relatado por Palací et al. (2004).

Estômatos: os estômatos são simples, sem especialização (células-guarda posicionadas ao mesmo nível das demais células epidérmicas, Tomlinson 1969), estão distribuídos paralelamente ao eixo da folha, e de forma aleatória. São constituídos por duas células-guarda e seis células subsidiárias: duas laterais, duas laterais externas e duas polares (Fig. 6a). Em secção transversal, observa-se que as células subsidiárias laterais adjacentes às células-guarda, estão em nível 
abaixo das demais do complexo estomático (Fig. 6b), sendo possível visualizar em vista frontal apenas uma pequena parte apical destas células, estas células são clorofiladas, e estão em contato com as células que circundam a câmara subestomática (Fig. 6a). Os estômatos estão presentes em ambas as faces da lâmina em $C$. berteroniana (Fig. 6c), e em C. sessiliflora são restritos à face abaxial da lâmina foliar (Fig. 6d). Estômatos em ambas as faces como encontrado neste trabalho é considerado uma exceção para a família, juntamente com Tillandsia usneoides (Tomlinson 1969).

Tomlinson (1969), ao relatar os estômatos de Bromeliaceae, usou como base o estudo ontogênico realizado por Krauss (1949) em Ananas comosus (L.) Merr., qual classifica as células do complexo estomático por sua estrutura e função na abertura e fechamento do poro estomático. Ao descrever os estômatos de Catopsis, Tomlinson (1969) atribui ao complexo estomático duas células-guarda, duas células subsidiárias laterais, duas células subsidiárias polares, e duas células laterais vizinhas. No entanto, Palací et al. (2004) atribuiu a Catopsis o tipo hexacítico de estômato. Segundo FrynsClaessens \& Cotthem (1973), o estômato hexacítico é o tipo cinco da categoria "Estômato Perigenous", a qual pertence os estômatos em que a célula estomática inicial divide apenas uma vez para produzir as duas células-guarda, e todas as demais células do complexo estomático são derivadas de células epidérmicas. Os estômatos das espécies estudadas são morfologicamente semelhantes ao tipo hexacítico de FrynsClaessens \& Cotthem (1973), porém devido à ausência de um estudo ontogênico dos estômatos do gênero Catopsis, não se pode afirmar que o mesmo pertence ao tipo hexacítico como proposto por Palací et al. (2004).

Neste trabalho, as células dos estômatos forem classificadas apenas com sua provável funcionalidade no complexo estomático. Onde: as células-guarda atuam efetivamente na abertura e fechamento do poro estomático; as células subsidiárias laterais são responsáveis pelo controle da pressão de turgor para a abertura e fechamento do poro pelas células-guarda e as células subsidiárias polares, contribuem para a diminuição da transpiração (Krauss 1949). As células chamadas de vizinhas por Tomlinson (1969) foram consideradas aqui como células subsidiárias laterais externas, pois é provável que estas células também sirvam para proteger os estômatos de tensões, uma vez que as células subsidiárias laterais estão com apenas uma pequena parte apical no nível das demais células do complexo. Com isso tanto as células subsidiárias polares como as laterais externas, apesar de não possuírem papel direto na abertura do poro estomático, devem ser importantes na manutenção do complexo estomático.

Célula epidérmica: em secção transversal, as células epidérmicas apresentam-se retangulares, com paredes periclinal interna e anticlinais espessas e citoplasma estreito (Fig. 7a). Em vista frontal as células epidérmicas da folha de ambas as faces são de formato quadrangular à retangular, paredes anticlinais sinuosas delgadas ou espessas, com um ou dois cristais esféricos de sílica (Figs. 6a, 7b-d). As variações no formato e sinuosidade das células epidérmicas são mais sutis em C. berteroniana (Fig. 7b) e mais acentuadas em C. sessiliflora (Figs. 6a, $7 \mathrm{c}, \mathrm{d})$, principalmente na bainha. A presença de corpos de sílica em Catopsis promove a redução da transpiração através da reflexão da luz (Tomlinson 1969), e proteção contra ataques herbívoros, por serem impalatáveis (Prychid \& Rudall 2000).

Hipoderme: unisseriada, presente em ambas as faces da folha, parenquimática ou esclerificada (Figs. 6c,d; 7e,f). Hipoderme parênquimátima, constituídas por células de paredes delgadas não lignificadas, de aspecto quadrangular está presente em ambas as faces de C. sessiliflora e na face adaxial de C. berteroniana (Figs. 6c,d). Hipoderme esclerificada, formada por células de paredes lignificadas de espessura delgada a extremamente espessa está presente apenas na bainha foliar da face abaxial de $C$. berteroniana (Fig. 7e,f), o que proporciona uma maior proteção mecânica e redução da transpiração para a folha da espécie (Tomlinson 1969)

Mesofilo: Em geral ambas as faces da lâmina e bainha foliar, o mesofilo apresenta camadas de parênquima aquífero subjacente às hipodermes (Figs. 6c,d; 7f,g). Entre as camadas de parênquima aquífero estão presentes feixes vasculares, canais de aeração, parênquima amilífero (bainha), parênquima clorofiliano homogêneo (lâmina) e células braciformes de prolongamentos curtos (Figs. 6c,d; 7f-h). As colunas de ar intercalam-se aos feixes vasculares (Figs. 6c,d; 7f,g). Na lâmina foliar o parênquima clorofiliano homogêneo circunda os feixes 

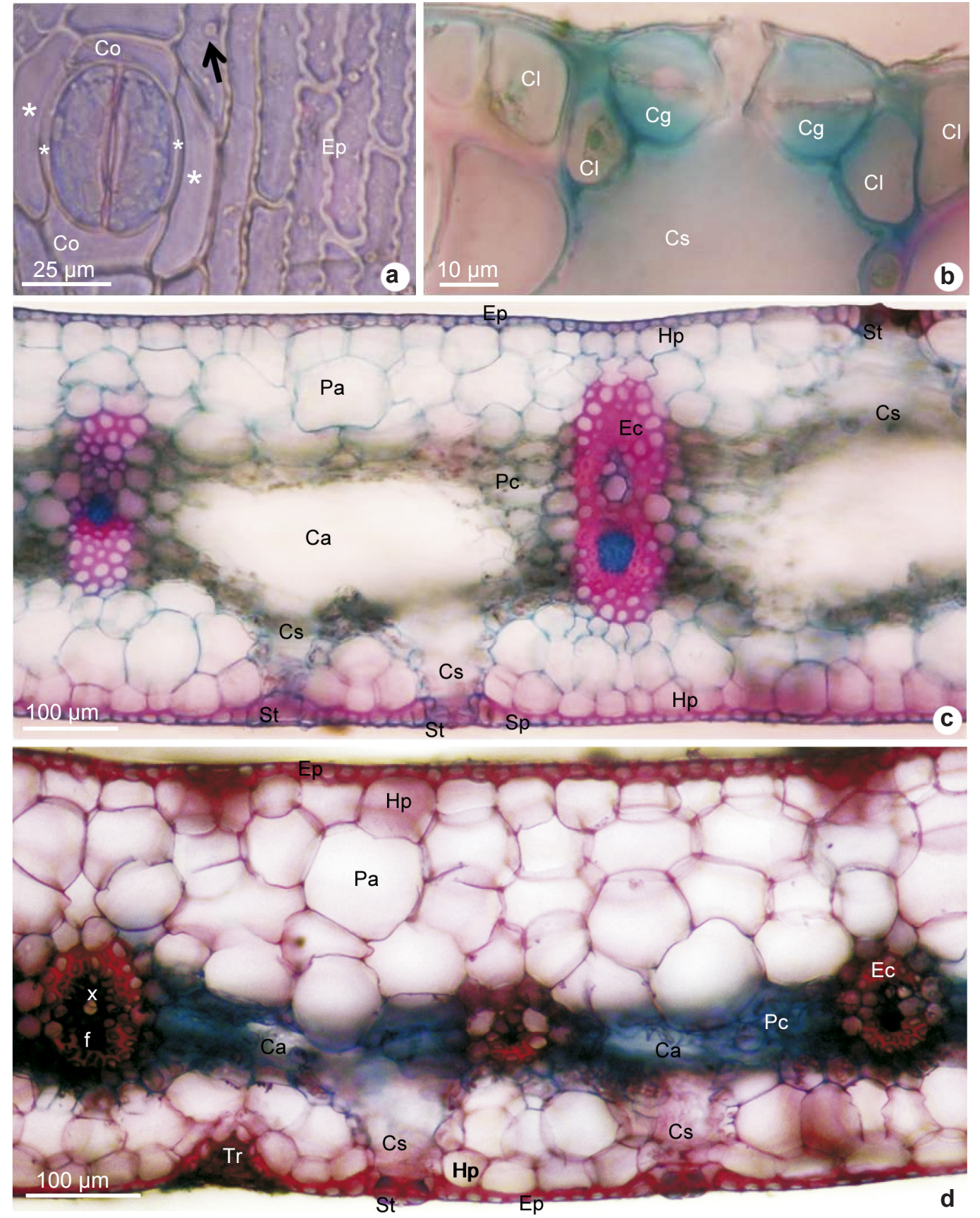

Figura 6 - a-d. Diferentes aspectos da lâmina foliar de Catopsis - a. secção paradérmica da face abaxial de Catopsis sessiliflora, detalhe do complexo estomático, formato das células epidérmicas, sílica (seta); b. secção transversal de $C$. berteroniana, detalhe do complexo estomático; c. secção transversal da lâmina de C. berteroniana. d. secção transversal da lâmina de $C$. sessiliflora. $\mathrm{Ca}=$ coluna de ar; $\mathrm{Cg}=$ células guarda; $\mathrm{Cl}=$ células laterais com cloroplasto; $\mathrm{Co}=$ células polares; $\mathrm{Cs}=$ câmara subestomática; $\mathrm{Ec}=$ feixes vasculares colaterais; $\mathrm{Ep}=$ célula epidérmica; $\mathrm{F}=$ floema; $\mathrm{Hp}=$ hipoderme; $\mathrm{Pa}=$ parênquima aquífero; $\mathrm{Pc}=$ parênquima clorofiliano; $\mathrm{Tr}=$ tricoma; $\mathrm{X}=$ xilema; $(*)$ indicam as células laterais do complexo estomático.

Figure 6 - a-d. Different aspects of the leaf of the Catopsis - a. paradermic section of the lower face of leaf of Catopsis sessiliflora; stomatal apparatus detail, format of the epidermal cells, silica (arrow); b. cross section of leaf of $C$. berteroniana, stomatal apparatus detail; c. cross section of $C$. berteroniana; $\mathrm{d}$. cross section of C.sessiliflora $\mathrm{Ca}=$ column of air; $\mathrm{Cg}=$ cells guards; $\mathrm{Cl}=$ side cells with chloroplasts; $\mathrm{Co}=$ polar cells; $\mathrm{Cs}=$ substomatic chamber; $\mathrm{Ec}=$ collateral vascular bundles (sclerenchyma) $\mathrm{Ep}=$ epidermal cell; $\mathrm{F}=$ phloem; $\mathrm{Hp}=$ hypodermis; $\mathrm{Pa}=$ aquifer parenchyma; $\mathrm{Pc}=$ homogeneous chlorophyll parenchyma; $\mathrm{Tr}=$ trichomes; $\mathrm{X}=\mathrm{xylem} ;(*)$ indicate the lateral cells of the stomatal apparatus detail. 
vasculares e partes ou totalmente as lacunas de ar (Fig. 6c,d), enquanto, na bainha foliar ambos estão em geral circundados por parênquima amilífero (Fig. 7f,g).

O parênquima aquífero é homogêneo e discreto, apresentam células volumosas, arredondadas de paredes delgadas (Fig. 7g), características comuns em Tillandsioideae (Derwidueé \& Gonzalez 2010). Apesar de não apresentar mucilagem evidente, as células se caracterizam como parênquima aquífero, principalmente por suas paredes sinuosas (Fig. $7 \mathrm{~g}$ ). Tomlison (1969) relacionou o parênquima aquífero menos pronunciado ao hábito epifítico e a presença de tanque, isso porque o tanque auxilia no armazenamento de água, porém Freschi et al. (2010) relatam que a combinação entre a presença de tanque externo nas epífitas, juntamente com o armazenamento interno de água na folha é a responsável pelo sucesso em períodos de ausência de água dessas plantas. Estes autores constataram que a região basal da folha é o local de maior armazenamento de água, o que pode ser visto em Catopsis pelo maior número de camadas de parênquima aquífero na bainha quando comparada a da lâmina foliar. A quantidade superior de tecido aquífero na bainha, está relacionada ao fato da região ter elevada densidade de tricomas absorventes em contato direto com a água presente no tanque (Freschi et al. 2010). As espécies analisadas frequentemente apresentam o mesofilo assimétrico, pois, uma das faces apresenta número maior de parênquima aquífero, ou células de diâmetro maior em uma das faces. Com isso os feixes vasculares, colunas de ar e células parenquimáticas possuem uma posição mais próxima da face com menor número de camadas de parênquima aquífero. Essa característica é mais frequente na bainha e lâmina de C. sessififlora (face adaxial com maior número de parênquima aquífero) (Figs. 6d, $7 \mathrm{~g}$ ), porém também ocorre em $C$. berteroniana, principalmente na bainha (face abaxial com maior número de parênquima aquífero). $\mathrm{Na}$ lâmina foliar $C$. sessiliflora apresenta na face adaxial 3-4 camadas de parênquima aquífero e na face abaxial 1-2 camadas (Fig. 6d), já em $C$. berteroniana as camadas são distribuídas mais uniformemente, contendo em geral, duas camadas em ambas às faces (Fig. 6c). Na bainha foliar $C$. sessiliflora possui na face adaxial 3-6 camadas de parênquima aquífero e na face abaxial 1-4 camadas (Fig. 7g), enquanto C. bertoroniana apresenta 2-6 camadas de parênquima aquífero na face adaxial e 3-6 camadas na face adaxial (Fig. 7f). Em ambas as espécies o parênquima aquífero pode conter reservas de amido na bainha (Fig. 7g).

As colunas de ar são preenchidas, em toda sua extensão, por parênquima braciforme de prolongamentos curtos (Fig. 7h) amelífero (bainha) ou clorofiliano (lâmina). Estas colunas estendem-se às câmaras subestomáticas, que se encontram revestidas de parênquima clorofiliano homogêneo (Fig. 6c). A presença de canal de aeração preenchido por parênquima braciforme foi relatada por inúmeros autores em diferentes espécies (Krauss 1949; Tomlinson 1969; Sousa et al. 2005). Santos-Silva et al. (2013), em Pitcairnioideae, relacionam os espaços intercelulares menores dessas células na coluna de ar com a presença de metabolismo C3 das espécies. Diferente do relatado por Tomlinson (1969), em Catopsis, não há diafragmas transversais ao longo da coluna de ar, estando esta continuamente preenchida pelas células braciformes. Esta coluna de ar que se estende por toda a folha, fornece uma conexão entre a atmosfera interna e externa, serve como reservatório de ar, e ainda regula as trocas gasosas (Krauss 1949).

Feixes vasculares colaterais de médio porte alternam-se com os de pequeno porte (Fig. 6c,d), uma característica frequente na família Bromeliaceae (Krauss 1949; Tomlinson 1969; Aoyama \& Sajo 2003; Sousa et al. 2005). Estes feixes apresentam fibras pericíclicas circundando-os completamente, ou restritas aos polos (Figs. 6c,d; 7f,g). Grãos de amido podem ser encontrados em todas as camadas do mesofilo da bainha excetuando-se na hipoderme esclereficada de C. berteroniana (Fig. 7f). Idioblastos com ráfides foram registrado no parênquima aquífero e no fundamental.

Nutrição: As espécies analisadas fazem parte do grupo de Bromeliaceae que tem sua nutrição depende de seu tanque: onde Catopsis berteroniana está na subdivisão carnívora, por suas modificações para captura de suas presas, e C. sessiliflora na subdivisão Animal- saprófitos, por abrigar uma microbiota rica, abundantes de detritívoros e saprófitos em suas axilas foliares (Benzing 2000). Apesar de estar na subdivisão carnívora em Bromeliaceae, C. berteroniana é protocarnivora, pois não produz secreções digestivas, os insetos presos em sua roseta são 

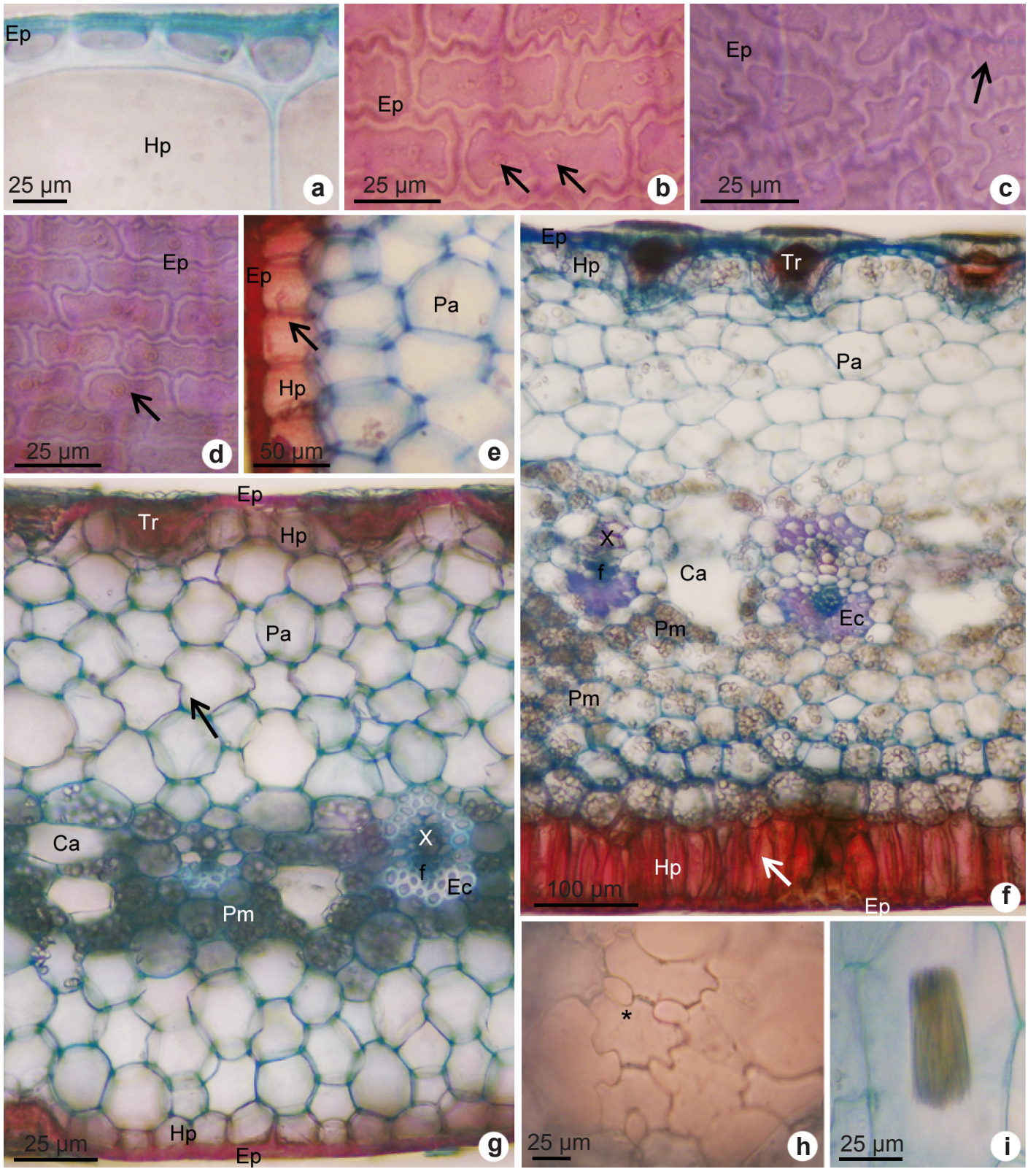

Figura 7 - a-i. Aspecto anatômico da folia do gênero Catopsis - a. secção transversal da lâmina de Catopsis berteroniana, células epidérmicas; b. secção paradermica da face adaxial de $C$. berteroniana, detalhe da espessura e sinuosidades das células epidérmicas; c-d. secção paradermica da face adaxial de C. sessiliflora, células epidérmicas de diferentes formas, espessura e sinuosidades; e. secção transversal da bainha de $C$. berteroniana, detalhe da hipoderme abaxial de paredes lignificadas delgada (seta); f. secção transversal da bainha foliar C. berteroniana, hipoderme abaxial de paredes lignificadas, extremamente espessa (seta); g. secção transversal da bainha foliar $C$. sessiliflora; h. detalhe do parênquima braciforme em C. berteroniana $\left(^{*}\right)$; i. idioblasto com ráfide.

Figure 7 - a-i. Anatomical aspect of leaf of the genus Catopsis - a. cross section of leaf of Catopsis berteroniana, detail of the lower of epidermal cell; b. paradermic section of upper side of $C$. berteroniana, epidermal cells detail, thickness and sinuosities; c-d. paradermical section of the adaxial surface of $C$. sessiliflora, epidermal cells of different shapes, thickness and sinuosities; e. cross section of leaf sheath of $C$. berteroniana, detail of the lower hypodermis with lignified walls, extremely thick (arrow); f. cross section of leaf sheath of $C$. berteroniana, detail of the lower hypodermis with thin lignified walls (arrow); g. cross section of leaf sheath of C. sessiliflora; h. detail of the stellated parenchyma in C. berteroniana $(*)$; i. idioblast of raphides, in the aquifer parenchyma. $\mathrm{Ca}=$ column of air; $\mathrm{Cg}=$ cells guards; $\mathrm{Cl}=$ side cells with chloroplasts; $\mathrm{Co}=$ polar cells; $\mathrm{Cs}=$ substomatic chamber; $\mathrm{Ec}=$ collateral vascular bundles (sclerenchyma); $\mathrm{Ep}=$ epidermal cell; $\mathrm{F}=$ phloem; $\mathrm{Hp}=$ hypodermis; $\mathrm{Pa}=$ aquifer parenchyma; $\mathrm{Pm}=$ parenchyma with starch content; $\mathrm{Pc}=$ homogeneous chlorophyll parenchyma; $\mathrm{Tr}=$ trichomes; $\mathrm{X}=\mathrm{xylem}$; 
decompostos por simbiontes, e posteriormente os nutrientes são absorvidos pelos tricomas absorventes (Benzing 2000). A alta densidade de cera em formato de bastões longos que se recurvam formando grandes emaranhados e a morfologia ereto tubular-afinalado do tanque proporcionam um eficiente método de captura em $C$. berteroniana. Essas características são responsáveis pela captura passiva e aprisionamento de uma ampla diversidade principalmente de insetos (Hymenoptera, Diptera, Coleoptera e Lepidoptera), além de aracnídeos, parasitas e insetos fitófagos em sua roseta (Fish 1976). O que proporcionam maior disponibilidade de nutrientes para a planta, o que faz com que $C$. berteroniana evita a concorrência direta com outras bromélias, uma vez que independe dos nutrientes do dossel da floresta e do solo (Fish 1976). Os insetos voadores são atraídos pela luz UV que é fortemente refletida pela cera, como um espelho. Como as fontes da luz UV são o sol e o céu, esta indica no interior da floresta espaço aberto para os insetos, que os usa como rota de fuga. Uma vez capturados para dentro da roseta de C. berteroniana, os insetos são impedidos de fugir pela cera presente na base das folhas, pois ela se desprende ao mais suave toque, envolvendo o inseto em uma provável escalada de fuga. A roseta tubular gradualmente afinalada conduz o inseto para as axilas foliares cheias d'água, onde serão decompostos e servirão para nutrir a planta via tricomas foliares (Fish 1976; Leme \& Maringo 1993).

O gênero Catopsis por incluir espécies epífitas com sistema radicular voltado para fixação e eventualmente para a absorção de água; tangue com fitotelmata bem desenvolvido, presença de tricomas absorventes na folha e metabolismo $\mathrm{C} 3$, enquadra-se no quarto tipo ecofisiológico da família Bromeliaceae (Benzing 2000). As características, cera epicuticular, epiderme de paredes espessas com presença de sílica e tricomas peltados absorventes, relatadas nas espécies estudadas, caracterizam-nas como plantas xeromórficas (Tomlinson 1969; Fahn \& Cuttler 1992; Benzing 2000). No entanto, elas também apresentam características de plantas mesofíticas, tais como, estômatos no mesmo nível que as células epidérmicas e parênquima aquífero pouco diferenciado. As espécies estudadas apresentam as características anatômicas foliares gerais da subfamília Tillandsioideae, tais quais, tricomas peltados com escudos e alas, ausência de sulcos na epiderme, mesofilo com hipoderme parenquimática, parênquima aquífero homogêneo, feixes colaterais, e parênquima clorofiliano braciforme presentes em câmaras de ar (Derwidueé \& Gonzalez 2010).

\section{Referências}

Aoyama EM \& Sajo MG (2003) Baker e espécies relacionadas (Bromeliaceae). Revista Brasileira de Botânica 26: 461-473.

Barfuss MHJ, Samuel R, Till W \& Stuessy TF (2005) Phylogenetic relationships in subfamily Tillandsioideae (bromeliaceae) basead on DNA sequence data from seven plastid regions. American Journal of Botany 92: 337-351.

Benzing DH (2000) Bromeliaceae: profile of an adaptive radiation. Cambridge University Press, New York. 655p.

Berlyn GP \& Miksche JP (1976) Botanical microtechnique and cytochemistry. Iowa State University, Ames. 326p.

BFG - The Brazil Flora Group (2015). Growing knowledge: an overview of seed plant diversity in Brazil. Rodriguésia 66: 1085-1113.

Butcher D \& Gouda EJ [continuously updated] The new bromeliad taxon list. Disponível em $<$ http://BromTaxonList.florapix.nl $>$. Acesso em 15 janeiro 2017. University Botanic Gardens, Utrecht.

Depiné P \& Oka Fiori C (2005) Análise ambiental da área do Sambaqui do Guaraguaçu, município de Pontal do Paraná, litoral do estado do Paraná, Brasil. Raega - O Espaço Geográfico em Análise 9: 107-122.

Derwidueé FS \& Gonzalez AM (2010) Anatomía foliar em Bromeliaceaedel nordeste Argentino y Paraguay. Bonplandia 19: 153-173.

Estades NP (2003) O litoral do Paraná: entre a riqueza natural e a pobreza social. Desenvolvimento e Meio Ambiente 8: 25-41.

Fidalgo O \& Bononi VLR (1989) Técnicas de coleta, preservação e herborização de material botânico. Reimpressão. Instituto de Botânica de São Paulo, São Paulo. 62p.

Fish D (1976) Structure and composition of the aquatic invertebrate community in habiting epiphytic bromeliads in South Florida and the discovery of an insectivorous bromeliad. Tese de Doutorado. Universidade da Florida, Florida. 78p.

Freschi L, Takahashi CA, Cambui CA, Semprebom TR, Cruz AB, Mioto PT, Versieux LM, Calvente A, Latansio-Aidar SR, Aidar MPMA \& Mercier $H$ (2010) Specific leaf areas of the tank bromeliad Guzmania monostachia perform distinct functions in response to water shortage. Journal of Plant Physiology 167: 526-533. 
Fryns-Claessens E \& Van Cotthem W (1973) A new classification of the ontogenetic types of stomata. Botanical Review 39: 71-138.

Givnish TJ, Millam KC, Berry PE \& Sytsma KJ (2007) Phylogeny, adaptive radiation, and historical biogeography of Bromeliaceae inferred from $n d h \mathrm{~F}$ sequence data. Aliso 23: 3-26.

Givnish TJ, Barfuss MHJ, Van Ee B, Riina R, Schulte K, Horres R, Gonsiska PA, Jabaily RS, Crayn DM, Smith JAC, Winter K, Brown GK, Evans TM, Holst BK, Luther H, Till W, Zizka G, Berry PE \& Sytsma KJ (2011) Phylogeny, adaptive radiation, and historical biogeography in Bromeliaceae: insights from an eight-locus plastid phylogeny. American Journal of Botany 98: 1-24.

Gonçalves EG \& Lorenzi H (2011) Morfologia vegetal: organografia e dicionário ilustrado de morfologia de plantas vasculares. $2^{\text {a }}$ ed. Instituto Plantarum de Estudos da Flora, São Paulo. 544p.

Haddad A, Sesso A, Attias M, Farina M, Meirelles MN, Silveira M, Benchimol M, Soares MJ, Barth OM, Machado RD, Souto-Padrón T \& Souza W (1998) Técnicas básicas de microscopia eletrônica aplicada às ciências biológicas. Sociedade Brasileira de Microscopia, Rio de Janeiro. 179p.

IUCN - International Union for Conservation of Nature (2016) Guidelines for application of IUCN red list of ecosystems categories and criteria. Version 1.0. IUCN, Gland. 94p. Disponível em $<$ https://portals.iucn.org/library/ node/45794>. Acesso em 30 janeiro 2017.

Johansen DA (1940) Plant microtechnique. McGrawHill, New York, London. 523p.

Kolattukudy PE (1980) Cutin, suberin, and waxes. In: Stumpf W \& Conn PM (eds.) The biochemistry of plants. Vol. 4. Academic Press, New York. Pp. 571-645.

Kowalski VK (2013) O grupo Vriesea platynema Gaudich. (Tillandsioideae, Bromeliaceae) no estado do Paraná: Aspectos taxonômicos e anatômicos. Dissertação de mestrado. Universidade Estadual de Ponta Grossa, Paraná. $117 \mathrm{p}$.

Kowalski VK, Pereira PPDA, Oliveira FMC, Costa ME \& Tardivo RC (2016) Are the wing's cells alive? Rodriguésia 67: 427-435.

Krauss BH (1949) Anatomy of the vegetative organs of the Pineapple, Ananascomosus (L.) Merr. (Continues) II. The Leaf. Botanical Gazette 110: 333-404.

Kraus JE \& Arduin M (1997) Manual básico de métodos em morfologia vegetal. Vol. 1. Editora da Universidade Federal Rural do Rio de Janeiro, Seropédica. $198 \mathrm{p}$.
Leme MCE \& Maringo LC (1993) Bromélias na natureza. Maringo Comunicação Visual, Rio de Janeiro. 184p.

Luther HE (2014). An alphabetical list of bromeliad binomials. $14^{\text {th }}$ ed. The Bromeliad Society International, The Marie Selby Botanical Gardens, Sarasota. 41p.

Martinelli G, Vieira CM, Gonzalez M, Leitman P, Piratininga A, Costa AF \& Forzza RC (2008) Bromeliaceae da Mata Atlântica brasileira: lista de espécies, distribuição e conservação. Rodriguésia 59: 209-258.

Palací CA, Brown GK \& Tuthill DE (2004) Vegetative morphology and anatomy of Catopsis (Tillandsioideae: Bromeliaceae). Selbyana 25: 138-150.

Peixoto AL \& Maia LC (2013) Manual de procedimentos para herbários. INCT-Herbário virtual para a flora e os fungos. Universitária UFPE, Recife. 97p.

Pierri N, Angulo RJ, Souza MC \& Kim MK (2006) A ocupação e o uso do solo no litoral paranaense: condicionantes, conflitos e tendências. Desenvolvimento e Meio Ambiente 13: 137-167.

Prychid CJ \& Rudall PJ (2000) Distribution of calcium oxalate crystals in monocotyledons. In: Wilson KL \& Morrison DA (eds.) Monocots: systematics and evolution. Csiro, Collingwood. $728 \mathrm{p}$.

Radford A, Dickson W, Massey J \& Bell C (1974) Vascular plants systematics. Harper \& Row, New York. 891p.

Reitz P (1983) Bromeliáceas e a malária - Bromélia endêmica. Flora Ilustrada Catarinense. Herbário Barbosa Rodrigues, Itajaí. 608p.

Santos-Silva F, Saraiva DP, Monteiro RF, Pita P, Mantovani A \& Forzza RC (2013) Invasion of the South American dry diagonal: what can the leaf anatomy of Pitcairnioideae (Bromeliaceae) tell us about it? Flora 208: 508-521.

Sass JE (1951) Botanicalmicrotechnique. 2 ${ }^{\text {a }}$ ed. Iowa State College Press, Ames. 391p.

Scharf U \& Gouda EJ (2008) Bringing Bromeliaceae back to homeland botany. Journal of the Bromeliad Society 58: 123-129.

Schuttz R, Araújo LC \& Sá FS (2012) Bromélias: abrigos terrestres de vida de água doce na floresta tropical.Natureza on line 10: 89-92.

Smith LB \& Downs RJ (1977) Tillandsioideae (Bromeliaceae). Flora Neotropica 14: 663-1492.

Sousa GM, Estelita MEM \& Wanderley MGL (2005) Anatomia foliar de espécies brasileiras de Aechmea subg. Chevaliera (Gaudich. ex Beer) Baker, Bromelioideae-Bromeliaceae. Revista Brasileira de Botanica 28: 603-613.

Stearn WT (1983) Botanical Latin. $3^{\text {rd }}$ ed. David \& Charles, Devon. 566p. 
Strehl T (1983) Forma, distribuição e flexibilidade dos tricomas foliares usados nas filogenias de Bromélias. Iheringia - Série Botânica. 31: 105-119.

Thiers B [continuously updated] Index herbariorum. New York Botanical Garden. Disponível em $<$ http.//http://sweetgum.nybg.org/science/ih/ > . Acesso em 16 fevereiro 2017.
Tomlinson PB (1969) Anatomy of the monocotyledons: III Commelinales-Zingiberales. Vol. 3. Clarendon Press, Oxford. 446p.

Wanderley MGL \& Martins S (2007) Bromeliaceae. In: Wanderley MGL, Shepherd GJ, Melhem TSA \& Giulietti AM (2007) Flora fanerogâmica do estado de São Paulo. Instituto de Botânica, São Paulo. Vol. 5, 494p.

\section{Lista de Exsicatas:}

Britez RM 1399 (1). Felitto G 289 (2). Hatschbach G 21193 (2), 21407 (2), 31800 (1), 32248 (2), 34874 (2), 61744 (2). Marcondes J 03 (2), 04 (2), 05 (2), 06 (2), 07 (2), 08 (2), 09 (1), 23 (1). Morokawa R 20 (2). Petean MP 45 (2). Silva J 1915 (1). Souza W 1299 (1). 